\title{
Jan Tinbergen, from Mathematics to Poverty and Environment
}

\author{
Aart de Zeeuw ${ }^{1,2}$ (D) \\ Published online: 4 February 2019 \\ (c) The Author(s) 2019
}

\begin{abstract}
Jan Tinbergen was a brilliant scientist, but he was also always available if the society called upon him. The government asked his help in designing macroeconomic policy in the post-war reconstruction of the Netherlands. However, soon he realized that the main problems in the world were poverty, war and the environment. Justice and good governance were the key in his thinking. Gradually the environment became his main concern. He has written two books, in Dutch: "Een Leefbare Aarde" ("A Livable Earth") in 1970, and "Kunnen Wij de Aarde Beheren?" ("Can We Manage the Earth?") in 1987. The first book is mainly about poverty and development but at the end, it touches upon the environment. In the second book, the environment has taken a prominent place. In this article, I will summarize what Jan Tinbergen has put forward in these books, in order to characterize the importance of his thinking and his contributions.
\end{abstract}

Keywords Poverty · War · Environment · Justice · Governance $\cdot$ Institutions

\section{Introduction}

When I started working, early 2007, as co-director of the Beijer Institute of Ecological Economics at the Royal Swedish Academy of Sciences in Stockholm, I thought of Jan Tinbergen. In 1969, the Academy awarded him, together with Ragnar Frisch, the first Prize in Economics in honor of Alfred Nobel, and the Beijer Institute represents one of the strong drives Jan Tinbergen developed during his life. The natural environment was one of his big concerns, and he consistently called out to the world to get together and take care of the issue. The Prize was awarded to him for his work in econometrics and macroeconomic modelling, but the fact that he moved

Aart de Zeeuw

A.J.deZeeuw@uvt.nl

1 Tilburg University, Tilburg, The Netherlands

2 Beijer Institute, Royal Swedish Academy of Sciences, Stockholm, Sweden 
from theoretical physics to economics was already a sign that his main interest was the society and mankind. He loved mathematics, but he wanted to serve humanity. Economics was a logical choice, especially in the times of crisis and post-war reconstruction.

Jan Tinbergen was a brilliant scientist, but he was also always available if the society called upon him. The government asked his help in designing macroeconomic policy in the post-war reconstruction of the Netherlands, and he was the first director of the so-called Centraal Planbureau. This institution still exists and plays an important role in policy support with quantitative economic analyses. However, soon he realized that the main problems in the world were poverty, war and the environment. Justice and good governance were the key in his thinking. He has been very active in stimulating policies for development. He calculated the $0.75 \%$ of GDP norm for development aid in 1970. He has also been an active member of Economists for Peace and Security. It is fair to say, however, that gradually the environment became his main concern. He has written two books, in Dutch: "Een Leefbare Aarde" ("A Livable Earth") in 1970, and "Kunnen Wij de Aarde Beheren?" ("Can We Manage the Earth?") in 1987. The first book is mainly about poverty and development but at the end, it touches upon the environment. In the second book, the environment has taken a prominent place. In this article, I will summarize what Jan Tinbergen has put forward in these books, in order to characterize the importance of his thinking and his contributions.

\section{2 "Een Leefbare Aarde"}

This book appeared in 1970, one year after Jan Tinbergen received the Prize in honor of Alfred Nobel. In English, the title reads "A Livable Earth". He got the Prize for his pioneering work in econometrics and macroeconomic modelling, but this book does not contain any formal econometrics or mathematical modelling. The book contains economics, yes, because Jan Tinbergen and many other economists in his generation believed that improving our understanding of economics and the way we organize our economic systems is crucial for solving the main societal issues.

The book starts with an extensive description of what poverty is and what it means for people, in an absolute and in a relative sense. Jan Tinbergen was strongly moved by this issue. It was clear to him that fighting poverty was world issue number one, and that this was needed to achieve welfare and peace in the world as a whole. He argued that poverty not only is a disgrace in itself, but also a source for tensions, conflicts and possibly war in case of large differences in income and wealth. Governments can also use wars to distract the attention away from poverty, and can use poverty to recruit soldiers. Poverty and war have been huge concerns of Jan Tinbergen all his life.

The environment is already an important part of his thinking at that time. When Jan Tinbergen describes production and the factors of production, he discusses nature as the first factor of production. There is no life without plants, soil and a good climate. Technological development in order to make better use of the natural resources is, of course, extremely important, but the need for life support cannot 
be ignored. In that sense, it is surprising that so many textbooks in economics have ignored the natural environment. This is fine in case of sufficient natural assimilation, so that life-support systems are not threatened. However, Jan Tinbergen was aware of potential problems and kept the natural environment as a factor of production besides capital, labor and knowledge. His main concern was that increasing production and changing ways of life would disturb ecological equilibria, which could be a threat to life and to welfare. In the book discussed later, he starts with poverty, war and environment as the three major issues that humanity has to solve.

A large part of the book is a quick course in economics. Jan Tinbergen is a master in connecting a deep knowledge of economics with aspects of culture, behavior and history, and in presenting everything in an accessible way. He writes at length about natural resources, location, different forms of capital, population growth, education, science, and comparative advantages. He also provides numbers whenever available, reflecting his background as an econometrician, in order to quantitatively support his analyses. An important topic is also the socio-economic system. Historically, society had moved from a feudal system, controlled by the landowners, to a capitalist system, controlled by the owners of the means of production. At the time, when Jan Tinbergen wrote his book, the split into capitalist systems, with social reform, and communist systems, with full control by the state, was dominating the discussion. He notes that the war economies during the First and Second World Wars were an historical factor resulting in some control by the state anyway. He turned away from the communist system because of the lack of economics and democracy, but he was a warm advocate of the mixed system, which had abolished child labor and introduced good education, social security and a progressive tax system. Jan Tinbergen was convinced that this system not only is more social, but also better for growth and development.

The main part of this book is on development. Jan Tinbergen's concern about poverty easily translates into the need for development of the poor countries. It was the time of the establishment of many international organizations where various plans for this development were discussed. Jan Tinbergen was very interested in this topic, and he was disappointed that everything went so slow, and that the member states often did not implement policies that would help the poor countries to develop: 50 years later the world has made some progress, but poverty is still there. He chaired a committee with the task to design a development strategy for the seventies of the last century. It showed his willingness to serve society and to advice policy-makers. Development economics has been his main field of study and work.

At the end of this book, Jan Tinbergen starts to express a more serious concern about the environment. The economic success had created a number of new problems, such as air pollution, water pollution, health issues, and the possible depletion of natural resources. He realized that alleviating poverty requires growth, but that an unlimited growth may destroy the natural environment. This is exactly the problem the Chinese government has been struggling with over the last decades. It had been easier for the Western world to develop without having to pay attention to environmental problems but given the current state of the natural environment, a combined development and environmental policy is needed. Jan Tinbergen already started to realize this 50 years ago. The developing countries had to catch up, but the world 
as a whole may have to be modest in order to respect the limits set by the Earth. He started to think about this more fundamentally. In the book that I will discuss next, he included the environment from scratch in his studies on how to manage the Earth and make it a livable place.

\section{3 “Kunnen Wij de Aarde Beheren?"}

This book appeared in 1987. In English, the title reads "Can We Manage the Earth?". In this book, Jan Tinbergen asks himself the three questions: "can we escape from the threats of war?", "can we prevent environmental destruction?", and "can we reduce extreme poverty in the Third World?". Things have changed but essentially, we are still facing the same problems. Europe is praised for preventing war for a very long time, but armed conflicts and threats of violence are still everywhere. The threat of environmental destruction, like climate change, is even more imminent. Poverty has been alleviated in parts of the world, but it still exists and the inequality is increasing. In general, Jan Tinbergen's answer to these questions is international cooperation. Of course, he understands the difficulties, but he sees no other way. In the preface to the book, he also shows how modest he is. He writes that these challenges require a broad interdisciplinary approach, and that he can only say something from the perspective of economics and physics. However, many people listen to him, because he has shown his brilliance in these two fields. Moreover, he does not have to be modest: he shows a broad knowledge about many things. He has been a big source of inspiration to very many people.

\subsection{Part I, Problems}

The book has three parts. In the first part, he writes about the history of the Earth and identifies the problems. The second and the third part are as in an economic textbook: the second part is on targets in managing the Earth, and the third part on instruments. The questions are bigger than usual, but he keeps the usual approach. In this article, I cannot summarize the whole book, but I will focus on what Jan Tinbergen writes on economics and, more specifically, on the relation with the environment.

First, we had economies without economics. In the last part of the eighteenth century, economics, a science for the systematic study of economies, started to accompany the development. The main target was to alleviate poverty, to raise material welfare, and to make better use of resources. Growth was the key concept. It is interesting to note that when Jan Tinbergen describes the basics of economics, he explicitly lists nature as an important factor of production. People nowadays argue that the environmental problems we are facing today may to some extent be caused by the fact that so many economists were trained with only capital and labor as factors of production. Things are changing, because in 2018 the Academy awarded the Prize in Economics in honor of Alfred Nobel to William Nordhaus, who developed a framework to study growth with negative feedback mechanisms via greenhouse gas 
emission and climate change. However, this was much later. Of course, at the time Jan Tinbergen wrote his book, we did not know much about climate change, but we could have listened to him and already included nature as a factor of production in economics, in order to be better prepared for this type of problems.

Jan Tinbergen introduces the term contraproduction: wars, natural disasters, mistakes, vandalism, drinking, smoking, drugs, and above all pollution of air, water and soil. It is interesting that he also explicitly mentions that people in the industrialized world eat too much meat and too much sugar, which leads to a decline in health. In current times, these issues get a lot of attention. All these things are occupying the news now. Jan Tinbergen was far ahead of his time. Evading taxes is, in his view, also a form of contraproduction, because it hampers a carefully designed optimal tax policy! It is not only unfair, but it is also not optimal. He always remains both the economist and the concerned human being. The only form of contraproduction that is positive for society is competition: competition destroys the inefficient production, but society needs this in order to move forward.

Around 1970 was the start of the Club of Rome, a group of ceo's and scientists, who commissioned the publication Limits to Growth by Meadows et al., a research group at MIT. The basic message was that the finiteness of the Earth, and thus the availability of resources, would put an end to growth at some point. The publication was heavily criticized, because it was ignoring the important economic feedback mechanisms of scarcity, higher prices, exploration and technological development. The discussion led to the famous bet between Paul Ehrlich and Julian Simon (Sabin 2013). Simon won, because actual developments were not in line with the predictions of the publication. Jan Tinbergen knew this, of course, and focused from the beginning on the real issue. Coordinated policy is needed in order to prevent a level of pollution that will disturb the balances of the Earth, and a shift is needed to resources that are infinite, such as the sun and human ingenuity. Again, he was ahead of his time. Nowadays, attention has shifted to planetary boundaries that indicate the threats to some of these balances (Rockström et al. 2009), and to research and the implementation of renewable energy sources, for example. However, coordinated international policy has not yet taken off. Jan Tinbergen would be very disappointed to see the series of the Conferences of the Parties in the United Nations Framework Convention on Climate Change dragging along. He would understand the difficulties, of course, but he would have a hard time seeing it happen.

\subsection{Part IIA, Targets}

In the second part of the book, Jan Tinbergen puts forward that the only answer to the challenges history sets upon us, is the deliberate management of the Earth as a whole. He does not believe that the split in sovereign states can produce proper management of the Earth. There are too many different interests, and therefore possible sources of conflict. He starts with distinguishing three targets for policy. The first one is what he calls the stage or the environment. It was clear that the selfcleaning mechanisms of nature could not manage everything anymore. Nowadays people say that we are in the Anthropocene, where human activities are affecting the 
state of the Earth (Crutzen 2002). He realizes that there is an ethical component, but he focuses on the economic interest of preserving the environment. Jan Tinbergen also realizes that technological development can sometimes support a sustainable welfare level, even if we gradually deplete a natural resource. In that sense, he was an environmental economist avant la lettre. The main target, however, remains the sustainable management of the Earth as a whole.

The second target for policy is the regular, but adjusted, set of socioeconomic targets: efficient production, sustainable growth, full employment, participation, education, optimal income distribution, optimal saving, and preventing contraproduction. Most of these targets were standard at the time. However, Jan Tinbergen explicitly added sustainability to growth. This is still not standard, 30 years later! Another important contribution was the idea of optimal income distribution. Of course, he understood the importance of incentives, so that people would make the best use of their talents, but he wanted a fair income distribution as well. This was partly political but in his view, this was also economics. For example, very large differences in income between the countries could lead to illegal immigration of citizens from poor countries into rich countries. Attempts to prevent this could lead to dangerous international tensions. We can see nowadays what he meant. In his terminology, contraproduction is the result, and that is not optimal. However, it seems that unconditional growth is the only target of most current politicians. Jan Tinbergen would be very sad seeing that.

The third target for policy is what he calls a positive peace. What he meant was that it is not sufficient to refrain from wars to settle conflicts. It is evenly important to create a society in which the probability of conflict is minimized. For a positive peace, rules are needed in case of joint exploitation of minerals or joint management of the oceans, for example. Jan Tinbergen already emphasized the need for international cooperation in order to manage acid rain and climate change, not only because this is efficient but also because it prevents possible conflicts that lead to contraproduction. It was typical for his generation of economists, who had experienced the Great Depression and the Second World War, to link economics to war, and to conclude that it was extremely important to build a stable economy in order to prevent the possible huge destruction when war breaks out. Jan Tinbergen was an active member of Economists for Peace and Security.

\subsection{Part IIB, Instruments}

In the third part of the book, Jan Tinbergen focuses on the instruments. He starts with describing how historically a myriad of institutions was formed, with differences in the different countries of the world. In his time, we still had capitalist based market economies and communist societies, but that distinction is not relevant anymore. His main concern is the lack of supranational institutions, especially in case issues need supranational decision-making. He criticizes the love for complete sovereignty: this is not possible anyway, in times of trade and other linkages between the countries. 
At this point, Jan Tinbergen explains external effects to his readership. Based on this, he defines the optimal level for decision-making as the lowest level where remaining external effects are negligible. He welcomes the establishment of the United Nations, with a number of connected institutions, and the start of the European Union, but he is concerned about the lack of power of these supranational institutions. For example, the United Nations Environment Programme should have the authority to deal with the factories that cause pollution in other countries, such as acid rain. We now know how long it took before a long series of negotiations between European countries led to policies in these countries for solving the acidrain problem. He is more optimistic about the European Union, but he also notes that small local short-term interests are constantly blocking developments that will be in the interest of everyone in the long term.

According to Jan Tinbergen, the two main questions are the following. Which policies should the institutions implement in order to reach the targets that were formulated in the previous part of the book, and which additional institutions are needed for that? As a starting point, he chooses environmental policy, because a healthy environment is basic (besides a healthy economy and safety), the issue is urgent (30 years ago!), and this policy requires supranational decision-making. Local pollution of air, water and soil can be regulated at the local level but pollution of a river, for example, has to be regulated at the supranational level of the countries involved. It is interesting here to note that in the early seventies, the Netherlands was paying France for preventing the release of waste from the salt mines in the Elzas on the river Rhine. This was not what Jan Tinbergen had in mind, but it was the outcome of a bargaining (in the sense of Coase) where France had the rights, and the Netherlands therefore had to pay. Jan Tinbergen would have questioned whether this was fair. The problem of acid rain that was mentioned earlier requires decisionmaking at the European level. The problem of climate change requires the global level. Jan Tinbergen was quite optimistic that supranational governance could be established. Nowadays we may be less optimistic after the series of failures in determining a clear global policy for preventing climate change. However, the general conclusion is the same: we must, there is no choice.

Jan Tinbergen then turns to the instruments that are needed to reach the targets that were formulated earlier. This part is not so much on the environment, except when he adds that efficient production should also be environmentally friendly and that growth should be sustainable. He clearly advocates what he calls the mixed system, in which private interest and markets are the basis, but where the weak people in the system are supported. He also strongly believes that this type of economy in the end will be more successful than a complete laissez faire. Of course, also in this part he is confronted with the need for supranational decision-making, especially when he discusses trade, employment opportunities and income distribution. In general, he emphasizes again that the supranational institutions need more power to handle the issues that have to be handled at that level. He writes less about instruments in the usual sense, like taxes and permits, because he feels that the institutional side is often ignored but that it is as important as the technical side.

The United Nations, with a number of specialized institutions under the umbrella of the UN, is the existing institution at the global level. Jan Tinbergen points out 
that we cannot expect the UN to be effective, if the representation in the UN does not reflect the actual power relations in the world. The decisions of the UN will be obstructed by countries that do not feel sufficiently represented in the decision process. He argues that it is the most democratic to base the number of votes on the size of the population but he realizes that it will be hard to ignore relative wealth and the contributions to the UN. He clearly struggles with this issue, and we regularly see the difficulties he points out for UN institutions: there is no easy solution.

Regarding additional global institutions that are needed under the umbrella of the UN, Jan Tinbergen suggests a World Treasury, with revenue raising in a proportional way, institutions for common resources as well as for outer space, and a police force. When he discusses institutions for common resources, he shows his political position and his concern for developing countries and poverty. For example, he explicitly refers to one of the ideas for the UN Convention on the Law of the Sea, which started in 1973 and concluded in 1982. The idea was that resources outside the exclusive economic zones of the countries were a common human heritage, and the revenues should primarily accrue to the developing countries. He was very disappointed that the USA objected to this, and refused to accept a UN institution for the exploitation of these resources. Jan Tinbergen was convinced that this was the right way to go, that this would reduce the tensions in the world, and therefore be beneficial for the future development.

At the end of the book, Jan Tinbergen considers integration. He distinguishes positive and negative integration. Negative integration refers to a joint decision to refrain from certain activities, such as the production of medium-range nuclear weapons. Positive integration means much more than that. Historically, we have seen many examples of integration of smaller jurisdictions into larger ones. The development of the European Union is a recent example. Jan Tinbergen sees the prevention of wars as one of the main benefits of integration. He would have been pleased to see the European Union receiving the Nobel Peace Prize in 2012 for that reason. However, he explicitly writes that with integration, he does not mean that countries just abolish policies in order to create a free internal market. Integration should be much more than that. He admires the vision, courage and creativity of Jean Monnet and the other founders of the EU in their quest for integration at a higher level. He would not be very pleased to see Great Britain wanting to leave the EU, and to see all the difficulties in establishing common EU policies.

Jan Tinbergen strongly believed in integration and powerful supranational institutions. It is clear that global issues require global management. One country cannot solve the problem of climate change, for example. However, up to now we have not been very successful. In 2009, the Academy awarded the Prize in Economics in honor of Alfred Nobel to Elinor Ostrom for her work on governing the commons in local communities (Ostrom 1990). She discovered ways to solve the tragedy of the commons (Hardin 1968). It has been, however, one of the wicked problems of our times to scale this up to the global level. On can say that Jan Tinbergen was an idealist, but one can also say that Jan Tinbergen was a realist, because he was convinced that life on Earth can only continue in the long run if humanity manages the Earth properly. 
In the epilogue to the book, Jan Tinbergen concludes that strong leaders, such as Jean Monnet, were needed to start integration in Europe. For integration at a higher level, even stronger leaders are needed. Awareness of possible large disasters may help and in that sense, he was close to the ideas behind the research on planetary boundaries and tipping points (Rockström et al. 2009). He concludes as follows: "One needed to think big in order to see and strive for a European federation. One needs to think even bigger to manage the world. Only by thinking big, and by acting accordingly, can we the people use our talents to continue our civilization and to help it fully blossom".

\section{Conclusion}

Humanity has produced many brilliant scientists. Humanity has also produced many people who devoted themselves to improving the world. However, not many people have done both. Jan Tinbergen is one of them. There are more, of course, but it is fair to say that Jan Tinbergen is a prominent one. He is highly respected for his scientific contributions and for his commitment to solve the major problems humanity is facing: poverty, war and environment. He always remained modest, in his way of life and in his writings. He was powerful, not in the usual sense, but just for who he was and in what he said and wrote. He deserves that we try to follow in his footsteps, in order to make the world a better place!

Open Access This article is distributed under the terms of the Creative Commons Attribution 4.0 International License (http://creativecommons.org/licenses/by/4.0/), which permits unrestricted use, distribution, and reproduction in any medium, provided you give appropriate credit to the original author(s) and the source, provide a link to the Creative Commons license, and indicate if changes were made.

\section{References}

Crutzen, P. J. (2002). Geology of mankind: The anthropocene. Nature, 415, 23.

Hardin, G. (1968). The tragedy of the commons. Science, 162(3859), 1243-1248.

Ostrom, E. (1990). Governing the commons. Cambridge: Cambridge University Press.

Rockström, J., et al. (2009). A safe operating space for humanity. Nature, 461(7263), 472-475.

Sabin, P. (2013). The Bet: Paul Ehrlich, Julian Simon, and our Gamble over Earths Future. New Haven: Yale University Press.

Tinbergen, J. (1970). Een Leefbare Aarde. Amsterdam/Brussel: Agon Elsevier.

Tinbergen, J. (1987). Kunnen Wij de Aarde Beheren?. Kampen: Kok Agora.

Publisher's Note Springer Nature remains neutral with regard to jurisdictional claims in published maps and institutional affiliations. 